\title{
Proton Induced X-ray Emission Study on the Content of Whale Tooth
}

\author{
M. H. Eisa ${ }^{1,3, *}$, H. Shen ${ }^{2}$, M. A. Alrajhi ${ }^{3}$, Hajo Idris ${ }^{3}$ \\ ${ }^{1}$ Physics Department, College of Science, Sudan University of Science technology, Khartoum 11113, Sudan \\ ${ }^{2}$ Institute of Modern Physics, Fudan University, Shanghai 200433, PR China \\ ${ }^{3}$ Physics Department, College of Science, Al Imam Mohammad Ibn Saud Islamic University Riyadh 11642, KSA
}

\begin{abstract}
The use of Ion beam technique for assaying small amounts of trace elements and major elements distribution has grown rapidly in recent years. Major and minor elemental composition of teeth has been extensively studied. In this work, elements content in teeth of whale were analyzed by the Proton Induced X-ray Emission (PIXE). This work is an attempt to investigate the history of mammal's different annual rings layer of whale tooth. High levels of Trace elements such as $\mathrm{Zn}$ and $\mathrm{Sr}$ were detected in the teeth. By analysis of elemental composition and evaluation of trace elements in different layer, the route of the whale movement and the status of pollution of environment were obtained. The result indicated that the technique is suitable to obtain minor and trace constituents of the teeth. The obtained results are discussed in detail and these results are compared withavailable data.
\end{abstract}

Keywords: Nuclear Technique; PIXE; Element; Whale Tooth

\section{Introduction}

Attentions have been paid to the analysis of tooth and bone for their important functions in the human and animal body [1-3]. However, the cells activities are regulated by tooth and bone matrix $[4,5]$. It has been shown that the imbalance of tooth and bone formation and tooth and bone resorption results in tooth and bone loss [6]. Tooth and bone mass is accumulated during childhood and young adulthood, reaching a peak at middle age $[7,8]$.

It has been shown that the imbalance of bone formation and bone resorption results in bone loss [6]. Bone loss with advancing age is observed in all human populations [7]. Although age-related bone loss occurs in both genders, it begins earlier and proceeds more rapidly in females [9]. Because of this, studies of agerelated bone loss have focused mainly upon women, although osteoporosis is a significant health problem in men. However, after the middle age, both men and women begin to lose bone mass as a normal part of aging, through an imbalance of the remodeling process [10]. As a result, bones become larger, heavier, and denser [11].

The methods which are widely used in the analysis of trace elements were reported elsewhere [12]. In this work, PIXE [13] was used to investigate the history of history of mammals by analyzing different annual rings layer of whale tooth. . Information about the trace elements in tooth is important for several reasons. (i) Most mammals have life spans that exceed 1 year. (ii) Information can be used for evaluation the environmental pollution in the Sea or Ocean (ii) Information also can be used to know the migration, seasons and the diets of mammals.

\subsection{Preparation of Sperm whale Tooth}

\section{Materials and Methods}

The Sperm Whale with the largest tooth was provided by Shanghai Fishers University. The length of the male sperm whale was 18.0 meters. Procedures: The tooth sample was cleaned with toothbrush (instruments China-made) several times. The tooth sample was chopped in deep about 1-5 $\mathrm{mm}$ as slice. The sample was polished with 600 golden sand paper grind to get a thick of $200 \mu \mathrm{m}$ and with 2000 golden sand paper extract grind to give the thick translucent of $150 \mu \mathrm{m}$. The sample was divided into several points according to the numbers of the structure growth layer. The structure growth of the whale tooth layers are given as: 0 year (at pregnant or embryo), 1 year (at born), 10 years (age), 15years (age), 20 years (age) and 25 years (age). The tooth slice was trapped and subjected to the PIXE analysis as shown in Figure 2.1. 


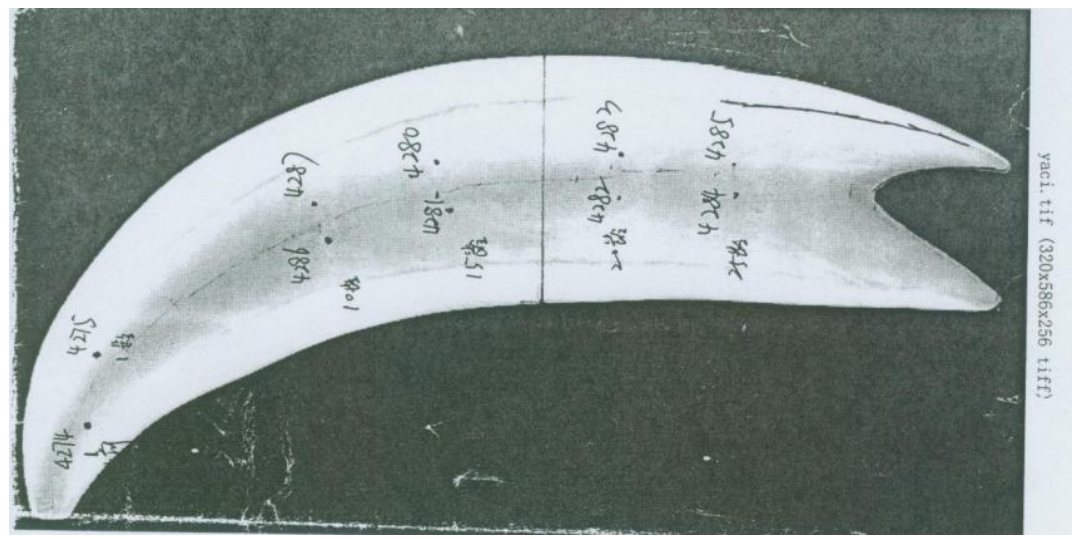

Figure 2.1.The slice of Sperm Whale Tooth

\subsection{External Beam PIXE}

External beam PIXE analysis was performed at the NEC-9SDH-2 Pelletron tandem accelerator at Fudan. The proton beam energy was $3 \mathrm{MeV}$. The proton beam leaves the vacuum system of the accelerator through a $7.5 \mu \mathrm{m}$ Kapton window. After passing through a short distance in air, the beam hits the target with a small spot of size $1 \mathrm{~mm}$ in diameter. X-rays emitted from the target are measured with a $\mathrm{Si}$ (Li) detector. The energy resolution of the detector was $180 \mathrm{eV}$ at $5.9 \mathrm{KeV}$. A thin $25.4 \mu \mathrm{m}$ beryllium window is placed in front of $\mathrm{Si}(\mathrm{Li})$ detector. The experimental setup in this study is designed as followings: The detector was positioned at $90^{\circ}$ with respect to the beam direction. The distance between the beam exit window and the target and between the target and the detector axis were each $10 \mathrm{~mm}$. The angles between the incident proton beam and the target $(\theta)$ and between the target and the detector axis $(\varphi)$ are each $45^{\circ}$. Each target was put into the external beam PIXE and bombarded with a $3.0 \mathrm{MeV}$ proton beam. The beam current was about $0.4 \mathrm{nA}$. During the measurements at least two spots on the sample surface were irradiated per run. The exposure time was 10 to 15 minutes. All the spectra were registered with Multi-channel buffer on 2048 channel pulse-height analyzer. The obtained spectra were kept in a PC-computer for analysis.

\section{Results and discussion}

The material under analysis came from Shanghai Fishers University. The structure growth of the whale tooth layers are given as: 0 year (at pregnant or embryo), 1 year (at born), 10 years (age), 15years (age), 20 years (age) and 25 years (age). The thus prepared samples served to determine the content of the following elements: $\mathrm{P}, \mathrm{S}, \mathrm{Ca}, \mathrm{V}, \mathrm{Mn}, \mathrm{Fe}, \mathrm{Ni}, \mathrm{Cu}, \mathrm{Zn}$, and $\mathrm{Sr}$ in sperm whale tooth, using PIXE method. The $\mathrm{Sr} / \mathrm{Ca}$ and $\mathrm{Zn} / \mathrm{Ca}$ ratios were also calculated. The ratios of the peaks areas of the micro and macro elements under study are shown in

Table 3.1.

Table 3.1 The Chemical composition inside each annual rings layer (unit: $\mathbf{1 0}^{-3}$ )

\begin{tabular}{|c|c|c|c|c|c|c|}
\hline Ratio & 0 Year & 1 Year & 10 Year & 15 Year & 20 Year & 25 Year \\
\hline $\mathrm{P} / \mathrm{Ca}$ & $51.61 \pm 0.77$ & $39.37 \pm 0.40$ & $63.71 \pm 0.26$ & 16.70 & $76.31 \pm 0.62$ & $82.50 \pm 0.41$ \\
\hline $\mathrm{V} / \mathrm{Ca}$ & $0.95 \pm 0.48$ & $0.78 \pm 0.27$ & $0.42 \pm 0.12$ & $0.82 \pm 0.48$ & n. d & n. $\mathrm{d}$ \\
\hline $\mathrm{Fe} / \mathrm{Ca}$ & $4.60 \pm 0.45$ & $6.14 \pm 0.25$ & $1.33 \pm 0.10$ & $1.72 \pm 0.36$ & $1.14 \pm 0.23$ & $1.70 \pm 0.14$ \\
\hline $\mathrm{Cu} / \mathrm{Ca}$ & $0.28 \pm 0.26$ & $0.81 \pm 0.13$ & $0.12 \pm 0.01$ & $0.48 \pm 0.48$ & n. d & $0.40 \pm 0.01$ \\
\hline $\mathrm{Zn} / \mathrm{Ca}$ & $32.27 \pm 0.58$ & $37.93 \pm 0.35$ & $18.57 \pm 0.15$ & $32.38 \pm 0.24$ & $20.32 \pm 0.33$ & $19.48 \pm 0.21$ \\
\hline $\mathrm{Sr} / \mathrm{Ca}$ & $17.37 \pm 0.40$ & $18.38 \pm 0.26$ & $10.57 \pm 0.10$ & $20.63 \pm 0.42$ & $10.98 \pm 0.23$ & $9.47 \pm 0.15$ \\
\hline
\end{tabular}

Note: $n$. d: no detected, peak area of the element ratio.

It was found that the ratio of $\mathrm{P} / \mathrm{Ca}$ inside different rings layer are very high compared to the ratios of the other elements as shown in Table 3.1. The $\mathrm{P} / \mathrm{Ca}$, is very low at 15 years -old, the specific value of $\mathrm{P} / \mathrm{Ca}$ is $16.704 \pm 0.518$ (unit: $10^{-3}$ ) (Figure 3.1). The elements $\mathrm{P}, \mathrm{Ca}, \mathrm{Fe}, \mathrm{Zn}$ and $\mathrm{Sr}$ are relatively high in whale tooth while, $\mathrm{V}, \mathrm{Ni}$ and $\mathrm{Cu}$ are very low levels. 


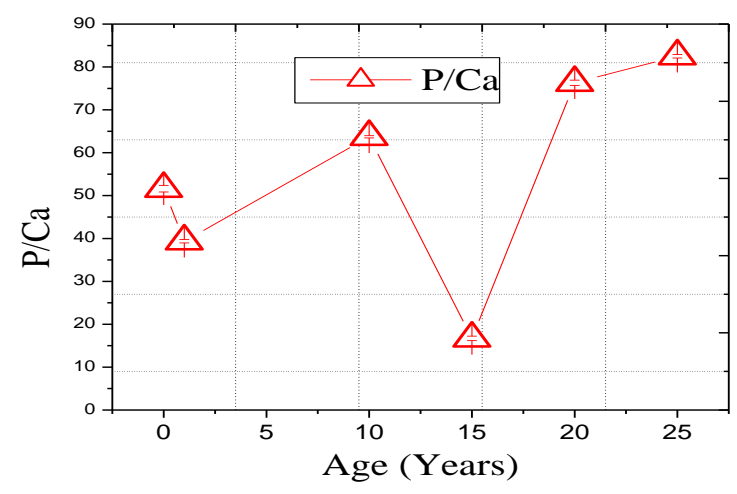

Figure 3.1 The $\mathrm{P} / \mathrm{Ca}$ ratio inside each annual rings layer

For Zinc and $\mathrm{Ca}$, statistically significant increases in the $\mathrm{Zn} / \mathrm{Ca}$ ratio with age of an individual were observed at (born, 1 years) $\left(37.93 \pm 0.35\right.$ ) (unit: $\left.10^{-3}\right) 1$ years (Figure 3.2). However, zinc and strontium in this study showed a different pattern of elemental profile. The chemical composition $\mathrm{Sr}$, since the embryo to the birth was gradually increased. At 10 years, the $\mathrm{Sr}$ value inside the annual rings layer was decreased, later on, from 10 years to 15 years, gradual increased then decreased gradually. Among the trace elements $\mathrm{Fe}, \mathrm{Zn}$, and $\mathrm{Sr}$ contents were relatively high compared to the other trace elements such as $\mathrm{V}, \mathrm{Cu}$ and $\mathrm{Ni}$ in all the samples. Therefore, we took notice of the annual rings layer change of the content $\mathrm{Zn}$ and $\mathrm{Sr}$.

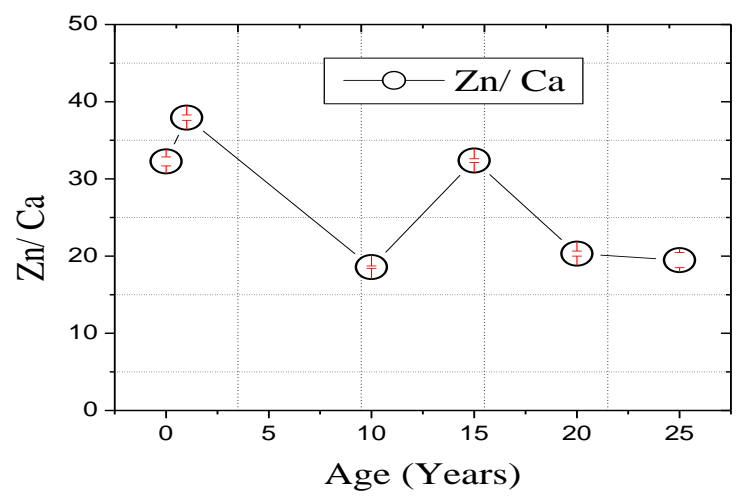

Figure 3.2 The $\mathrm{Zn} / \mathrm{Ca}$ ratio inside each annual rings layer

Figure 3.2 shows the relation between the ratios of $\mathrm{Zn} / \mathrm{Ca}$, and age of annual rings of tooth. The relation between the ratios of $\mathrm{Sr} / \mathrm{Ca}$ and annual rings age of tooth is given in Figure 3.3. Annual change of the $\mathrm{Zn}$ and $\mathrm{Sr}$ indicated the same tendency; both elements were higher in born, but lower in elderly age. This fact suggests that annual pattern for living of the whale tooth reflects the change of $\mathrm{Zn}$ and $\mathrm{Sr}$ content since $\mathrm{Zn}$ are the essential elements for mammals but $\mathrm{Sr}$ is not. The migration behavior may cause annual change of the $\mathrm{Zn}$ and Sr Content. Moreover, patterns such as trace element volumes due to the different environment remain forever encoded in the teeth since the teeth do not decalcify unlike bone.

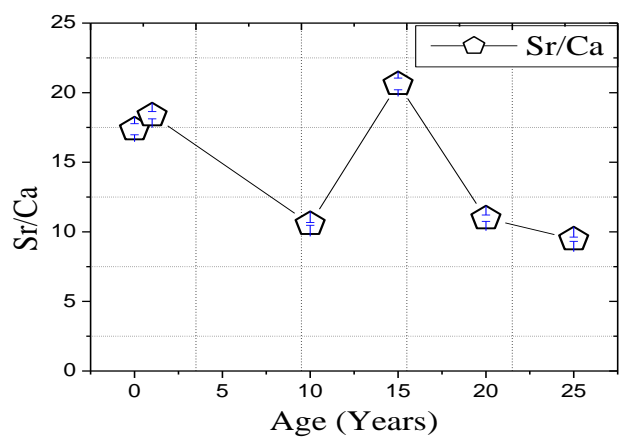

Figure 3.3 The $\mathrm{Sr} / \mathrm{Ca}$ ratios inside each annual ring layer 
A PIXE analysis was performed to investigate the annual individual patterns. Figure 3.4 shows the relation between the ratios of $\mathrm{Mn} / \mathrm{Ca}, \mathrm{Fe} / \mathrm{Ca}, \mathrm{Ni} / \mathrm{Ca}$ and $\mathrm{Cu} / \mathrm{Ca}$, and age. These elements may give indication about the influence of environmental factors, pollution and movement of whale.

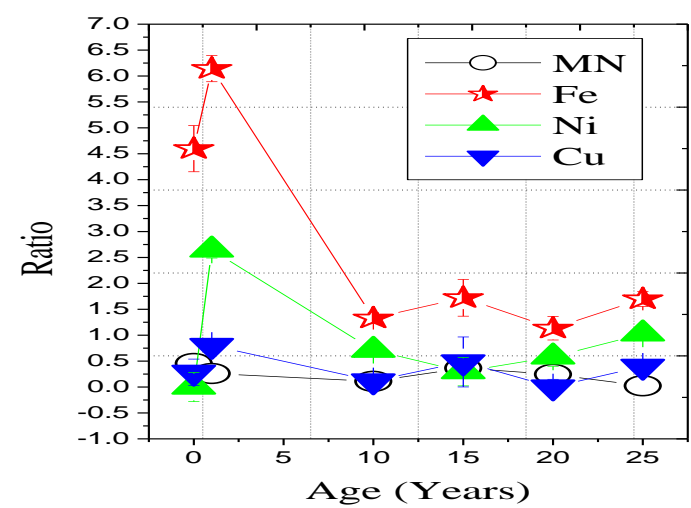

Figure 3.4 The $\mathrm{Mn} / \mathrm{Ca}, \mathrm{Fe} / \mathrm{Ca}, \mathrm{Ni} / \mathrm{Ca}, \mathrm{Cu} / \mathrm{Ca}$ ration in Whale Tooth

In the course of examination, statistically significant differences were found between the content of the elements studied in different annual rings layer of a whale tooth. The results can reflect environmental and living conditions of the whale, dietary habits and uptake of some elements. Tooth has been indicated as dose monitors for elemental exposure. However, the results clearly show that the elemental levels inside annual rings layer are different.

\section{Conclusion}

From study on whale tooth, the results may give indication about the influence of environmental factors, pollution, living conditions, uptake of some elements and movement of whale.

\section{Acknowledgements}

The authors wish to acknowledge the excellent experimental conditions provided by the group of Accelerator Laboratory of Fudan University.

\section{References}

[1]. J. B. Beattie and A. Avenell, Nutrition Research Review, 5 (1992) 167-188

[2]. F. Peters, K. Schwarz, M. Epple, Thermochimica Acta 361 (2000) 131-138

[3]. J. Yoshinaga, T. Suzuki and M. Morita, Sci Total Environ. 79(3) (1989) 209-21

[4]. L. Knott, and A. J. Bailey, C, Bone 22 (1998) 181-187

[5]. J. A. Buckwalter, M. J. Glimcher, R. R. Cooper and R. Recker, Instr. Course Lect. 45 (1996) 371-386

[6]. M. Gunness-Hey and j. m. Hock, Metab Bone Dis Rel Res 5 (1984) 177-181

[7]. R. B. Mazess, Clin Orthop 165 (1982) $239-252$

[8]. R. J. COLMAN, M. A. LANE, N. BINKLEY et al., Bone 24 (1) (1999) 17-23

[9]. S. Hough, Fast and slow bone losers. Drugs Aging, 12 (1998)1-7.

[10]. J. Aerssens, S. Boonen, J. Joly and J. Dequeker, Journal of Endocrinology 155, (1997) 411-421

[11]. M. B. Andrew, M. G. Alison, D. W. John et al., Int J Med Sci 1(2004)170-180

[12]. M. F. Basle, Y. Mauras, M. Audran, P. Clochon, A. Rebel, P. Allain, J Bone Miner Res, 5(1) (1990) 41-7

[13]. S. A. E. Johansson, J. L. Campbell, PIXE, A Novel technique for Elemental Analysis, Wiley, Chichester, (1988)

\section{List of Figures}

Figure 3.1 The $\mathrm{P} / \mathrm{Ca}$ ratio inside each annual rings layer

Figure 3.2 The $\mathrm{Zn} / \mathrm{Ca}$ ratio inside each annual rings layer

Figure 3.3 The $\mathrm{Sr} / \mathrm{Ca}$ ratios inside each annual ring layer

Figure 3.4 The $\mathrm{Mn} / \mathrm{Ca}, \mathrm{Fe} / \mathrm{Ca}, \mathrm{Ni} / \mathrm{Ca}, \mathrm{Cu} / \mathrm{Ca}$ ration in Whale Tooth

\section{List of Tables}

Table 2.1 Main characteristics and parameters of PIXE Set-Ups

Table 3.1 The chemical composition inside each annual rings layer (unit: $\mathbf{1 0}^{\mathbf{- 3}}$ )

\section{Paper Information:}

Text File: Microsoft Word XP Professional

Graphics format: TIFF

Font: Times 
Page No.: 9

Table No. : 2

Figure No.: 4 